\title{
Curvularia lunata: A fungus for possible berberine transformation
}

\author{
Deniz Yilmaz (iD), Fatma Gizem Avci (iD) 2, , Berna Sariyar Akbulut (i) 1
}

\begin{abstract}
${ }^{1}$ Marmara University, Faculty of Engineering, Department of Bioengineering, Istanbul, Turkiye
${ }^{2}$ Uskudar University, Faculty of Engineering and Natural Sciences, Department of Bioengineering, Istanbul, Turkiye
\end{abstract}

\begin{abstract}
The prevalence of multidrug-resistant microorganisms results in an urgent need for the development of new antimicrobial agents or new treatment strategies. In this sense, plants serve different alternatives. Berberine, a plantderived compound, is one of the alkaloids known to display antimicrobial activity against several types of microorganisms, while its being a substrate of various efflux pumps causes a decrease in its efficacy. Biotransformation makes it possible to obtain novel or more effective compounds with only minor structural modifications using enzyme systems. In this study, biotransformation of berberine by Curvularia lunata was examined. The working concentration of berberine was determined by observing the microbial growth on agar plates. The concentration of residual berberine in the media was analyzed by HPLC. In addition, laccase and beta-glucosidase enzyme activities were followed for their possible roles during the biotransformation of berberine. The results show that at the end of 14 days, C. lunata consumed $99 \%$ and $87 \%$ of berberine with the initial concentrations of $0.35 \mathrm{mg} / \mathrm{mL}$ and 0.5 $\mathrm{mg} / \mathrm{mL}$, respectively. Enzyme activities were not affected significantly. Since the concentration of berberine decreased, the biotransformation of berberine by C. lunata could be mentioned. Monitoring of biotransformation products plays a crucial role in discovering novel antimicrobial compounds and new valuable molecules.
\end{abstract}

\section{ARTICLE HISTORY}

Received: Sep. 17, 2021

Revised: Jan. 30, 2022

Accepted: Feb. 16, 2022

\section{KEYWORDS}

Biotransformation,

Berberine,

Curvularia lunata,

Antimicrobial resistance.

\section{INTRODUCTION}

Biotransformation is defined as the process in which biological systems (cells or enzymes) convert chemical compounds into structurally related products (Eliwa et al., 2021; Liu \& Yu, 2010; Sultana, 2018). It has numerous advantages over chemical methods/organic synthesis such as having high regio-/stereo-/enantiospecificity, mild process conditions, and lower costs and being environmentally friendly (Rozzell, 1999; Sultana, 2018). Biotransformations are generally composed of acetylation, esterification, glycosylation, hydrolysis, hydroxylation, isomerization, methylation, oxidation, and reduction reactions which can result in the formation of several intermediates and final compounds. These products of biotransformation have been used in agrochemical, food, pharmaceutical, and other industries for centuries (Fura, 2006; Giri et al., 2001; Pervaiz et al., 2013). Additionally, biotransformation reactions are applied for the

\footnotetext{
*CONTACT: Fatma Gizem Avci $\varangle$ gizemavci@gmail.com Uskudar University, Faculty of Engineering and Natural Sciences, Department of Bioengineering, Istanbul, Turkiye
} 
specific conversion of natural compounds such as alkaloids, steroids, and terpenoids using different catalysts like plant cells, microbial cells, or isolated enzymes to obtain their derivatives (Liu \& Yu, 2010). Microbial biotransformation is an important part of white biotechnology and gains prominence in the pharmaceutical industry due to its numerous advantages including lowcost and simple repetitive processes, large amounts of biomass production in a short time, novel, more active, or less toxic products from natural or synthetic compounds, and ease of scale-up (Bianchini et al., 2015).

Antimicrobial resistance has been regarded as one of the most important health concerns and natural products are promising candidates to overcome this problem with their divergent structures and multi-target properties (Avci et al., 2018). In addition, natural products are valuable sources of drug leads. Biotransformations have become crucial for the structural diversification of natural compounds and led to optimization in drug discovery and development (Venisetty \& Ciddi, 2003). The biotransformation of many natural products including phytosterols, steroids, terpenes, alkaloids, and flavonoids by different bacteria and fungi has been reported in the literature (Bukvicki et al., 2021).

In the light of given information, this current study aims to examine the biotransformation of berberine by the fungus Curvularia lunata, a microorganism preferred for biotransformation due to its capacity to transform natural substrates (Collins et al., 2001; Schmeda-Hirschmann et al., 2004). No work about the biotransformation of berberine by $C$. lunata has been found during our literature research.

\section{MATERIAL and METHODS}

\subsection{Chemicals and Microorganism}

Berberine chloride hydrate (CAS No. 141433-60-5) and all other chemicals were purchased from Sigma-Aldrich.

Curvularia lunata ATCC 12017 was obtained from the American Type Culture Collection (Manassas, Virginia, US).

\subsection{Effect of Berberine on C. lunata Growth}

To determine the effect of berberine on the growth, the radial growth of $C$. lunata was followed. Cut mycelial discs $(1 \times 1 \mathrm{~cm})$ from 7-days grown fungi were placed at the center of potato dextrose agar (PDA) plates containing different berberine concentrations $(0,0.1,0.35,0.5,1,2$ $\mathrm{mg} / \mathrm{mL}$ ). The growth was followed for 14 days at $24{ }^{\circ} \mathrm{C}$ and expressed in $\mathrm{mm}$ by measuring the diameter of the colony.

\subsection{Biotransformation of Berberine}

The biotransformation experiments were carried out in $50 \mathrm{~mL}$ of potato dextrose broth (PDB) inoculated with 7-days grown $C$. lunata on $1 \times 1 \mathrm{~cm}$ agar discs. Berberine was added to 3-days grown cells in PDB with a final concentration of $0.35,0.5$, and $1 \mathrm{mg} / \mathrm{mL}$. Cells were incubated at $24{ }^{\circ} \mathrm{C}$ and $114 \mathrm{rpm}$ for 14 days. The control culture was grown without berberine under identical conditions.

\subsection{Analysis of Residual Berberine Amount Using HPLC}

The concentration of the residual berberine in media was monitored by high-performance liquid chromatography (HPLC) system with a reverse-phase Poroshell 120® C18-EC $(50 \times 4.6 \mathrm{~mm}$ i.d. and 2.7- $\mu \mathrm{m}$-film thickness) column. The column temperature was $30^{\circ} \mathrm{C}$ and the injection volume was $20 \mu \mathrm{L}$. A solution of $\mathrm{Acn}: \mathrm{H}_{2} \mathrm{O}$ (1:9) was used as the mobile phase at a flow rate of $0.6 \mathrm{~mL} / \mathrm{min}$. Samples collected after the $0^{\text {th }}, 8^{\text {th }}$, and $14^{\text {th }}$ days of biotransformation were filtered through a $0.22 \mu \mathrm{m}$ pore size syringe filter and injected into HPLC. The analyses were carried out using at least three replicates. 


\subsection{Enzymatic Studies}

Laccase and beta-glucosidase activities were measured to examine their effects on the biotransformation of berberine at different concentrations $(0-1 \mathrm{mg} / \mathrm{mL})$. Samples were collected after 0,8 , and 14 days of incubation. The mycelia were separated from the fungal culture using Whatman filter paper and then the culture was filtered through a $0.22 \mu \mathrm{m}$ pore size filter. Culture broth without berberine was used as the control. Enzyme activities were measured using at least three replicates.

\subsubsection{Laccase activity assay}

Laccase activity was determined by measuring the oxidation of the substrate 2, 2'-azino-bis(3ethylbenzothiazoline-6-sulphonic acid) - ABTS. The assay mixture containing $950 \mu \mathrm{L}$ acetate buffer $(0.1 \mathrm{M}, \mathrm{pH} 4.5), 200 \mu \mathrm{L}$ ABTS $(15 \mathrm{mM})$, and $50 \mu \mathrm{L}$ sample was incubated at room temperature for $30 \mathrm{~min}$. The absorbance was read at $420 \mathrm{~nm}$ using spectrophotometer. One unit (U) of laccase activity was defined as the enzyme amount which oxidizes $1 \mu \mathrm{mol}$ of ABTS per minute under the assay conditions.

Laccase activity was calculated through the equation below:

$$
\mathrm{U} / \mathrm{L}=[(\Delta \mathrm{A} / \mathrm{t}) / \varepsilon . \mathrm{d}] \times\left(1 \times 10^{6} \mu \text { mole } / \text { mole }\right) \times\left(\mathrm{V}_{\mathrm{t}} / \mathrm{V}_{\mathrm{s}}\right)
$$

$\Delta \mathrm{A}$ : Absorbance change at $420 \mathrm{~nm}\left(\Delta \mathrm{OD}\right.$ : $\left.\mathrm{OD}_{\text {assay }}-\mathrm{OD}_{\text {blank }}\right)$

$\mathrm{t}$ : Reaction time (30 min)

$\varepsilon$ : Extinction coefficient of the substrate $\left(36000 \mathrm{M}^{-1} \mathrm{~cm}^{-1}\right)$

d: Lightpath $(1 \mathrm{~cm})$

$\mathrm{V}_{\mathrm{t}}$ : Total reaction volume $(1.2 \mathrm{~mL})$

$\mathrm{V}_{\mathrm{s}}$ : Sample volume $(0.05 \mathrm{~mL})$

\subsubsection{Beta-glucosidase activity assay}

Beta-glucosidase activity was measured using 4-Nitrophenyl $\beta$-D-glucopyranoside - pNPG as the substrate. The assay mixture containing $800 \mu \mathrm{L}$ acetate buffer $(0.1 \mathrm{M}, \mathrm{pH} 4.5), 100 \mu \mathrm{L}$ pNPG $(10 \mathrm{mM})$, and $100 \mu \mathrm{L}$ sample was incubated at $45{ }^{\circ} \mathrm{C}$ for $15 \mathrm{~min}$. After the addition of 1 $\mathrm{mL} \mathrm{Na}_{2} \mathrm{CO}_{3}(1 \mathrm{M})$ to the mixture to stop the reaction, the absorbance was read at $420 \mathrm{~nm}$. One unit $(\mathrm{U})$ of beta-glucosidase activity was defined as the enzyme amount required to release 1 $\mu$ mole of $\mathrm{pNP}$ ( $\mathrm{p}$-Nitrophenol) per minute under the assay conditions.

Beta-glucosidase activity was calculated through the equation below:

$$
\mathrm{U} / \mathrm{mL}=[(\Delta \mathrm{A} / \mathrm{t}) / \varepsilon . \mathrm{d}] \times\left(\mathrm{V}_{\mathrm{t}} / \mathrm{V}_{\mathrm{s}}\right)
$$

$\triangle \mathrm{A}$ : Absorbance change at $420 \mathrm{~nm}$

t: Reaction time (15 min)

$\varepsilon$ : Extinction coefficient of the substrate $\left(18.1 \mathrm{~cm}^{2} / \mu\right.$ mole $)$

d: Lightpath $(1 \mathrm{~cm})$

$\mathrm{V}_{\mathrm{t}}$ : Total reaction volume $(1 \mathrm{~mL})$

$\mathrm{V}_{\mathrm{s}}$ : Sample volume $(0.1 \mathrm{~mL})$

\section{RESULTS and DISCUSSION}

The prevalence of multidrug-resistant microorganisms causes a serious worldwide health crisis. The development of new antimicrobials or improvement of the effectiveness of current ones might be a solution to this alarming problem. Plant-derived substances are promising sources in antimicrobial drug design. Berberine is a valuable alkaloid in the search for effective and novel antimicrobial compounds with its antimicrobial activity against several types of 
microorganisms. However, being a substrate of many multidrug efflux pumps in microorganisms reduces its efficacy.

Biotransformation is a process used to develop metabolites with greater pharmacological activities. Minor structural modifications in the substances can be done through different reactions performed by enzyme systems (Bianchini et al., 2015). Biotransformation is also considered to decrease the toxicity of a drug and transform it into a more polar and easily excreted metabolite in the pharmaceutical industry (Pervaiz et al., 2013). In the current study, experiments for the biotransformation of berberine using $C$. lunata were performed.

\subsection{Determination of Berberine Working Concentration and Addition Time}

\subsubsection{Effect of berberine on C. lunata growth}

To determine the berberine working concentration, fungal growth on PDA plates containing 0 , $0.1,0.35,0.5,1$, and $2 \mathrm{mg} / \mathrm{mL}$ concentrations of berberine was observed.

Figure 1. Radial growth of $C$. lunata in the presence of different berberine concentrations.

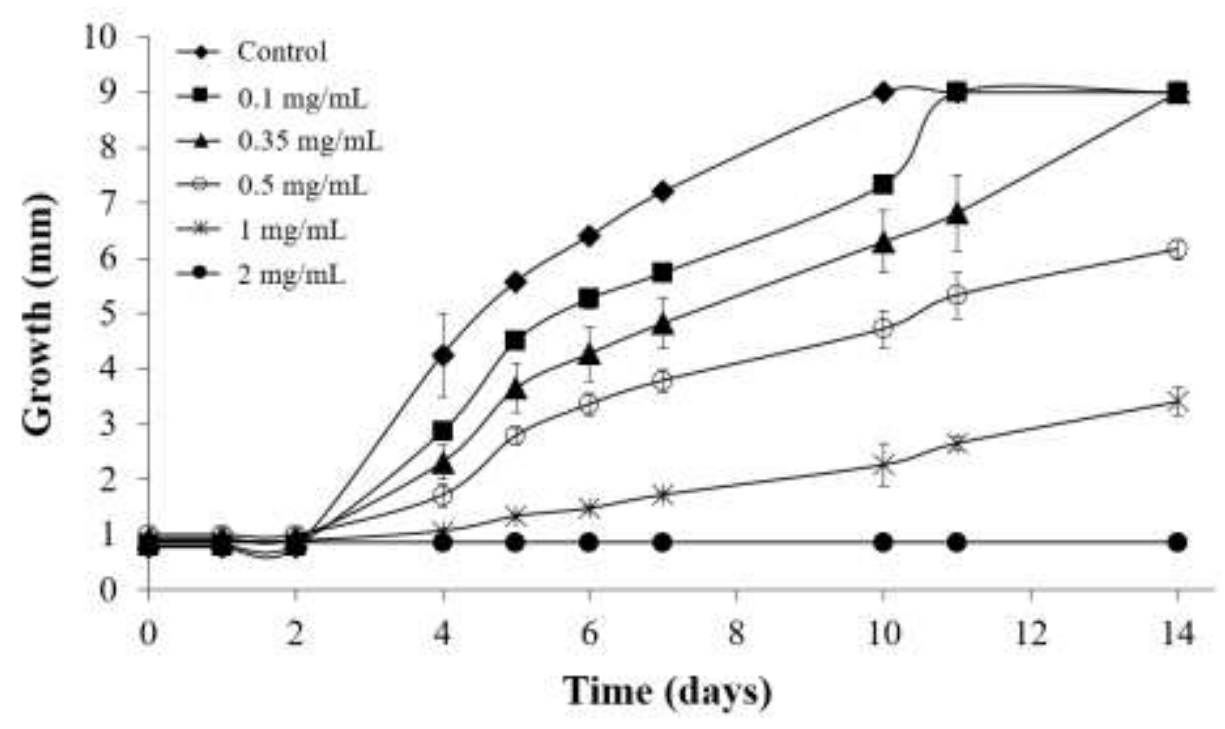

Figure 1 and Table 1 show that the growth (rate) in PDA plates decreased with the increasing berberine concentrations. At the end of 14 days of incubation, the PDA plates with 0.1 and 0.35 $\mathrm{mg} / \mathrm{mL}$ berberine concentrations were covered with $C$. lunata completely although the growth was initially slower. The growth rate dropped to $50 \%$ with $0.5 \mathrm{mg} / \mathrm{mL}$ berberine and it was seen that the whole PDA plate was not covered with the fungal cells. It was observed that $C$. lunata growth was inhibited much when berberine concentration was $\geq 1 \mathrm{mg} / \mathrm{mL}$. The radial growth was very slow at $1 \mathrm{mg} / \mathrm{mL}$ concentration while $2 \mathrm{mg} / \mathrm{mL}$ berberine completely inhibited the cell growth. The radial growth of the fungus increased with the longer incubation periods.

Table 1. Radial growth rates $\left(\mathrm{mm} \cdot \mathrm{day}^{-1}\right)$ of $C$. lunata at different berberine concentrations.

\begin{tabular}{cc}
\hline Berberine Concentration $(\mathrm{mg} / \mathrm{mL})$ & Radial Growth Rate $\left(\mathrm{mm}^{\left.- \text {day }^{-1}\right)}\right.$ \\
\hline 0 & 0.818 \\
0.1 & 0.724 \\
0.35 & 0.634 \\
0.5 & 0.464 \\
1 & 0.176 \\
2 & 0 \\
\hline
\end{tabular}




\subsubsection{Determination of the berberine addition time}

The chemicals used in biotransformation may inhibit cell growth. Thus, if these compounds were added to the media with the inoculum simultaneously, there would be no biomass to carry out the biotransformation. Therefore, the process initiation time was investigated. As expected, there was no growth when berberine was added to the fresh PDB together with the $C$. lunata cells. A reasonable growth was observed when berberine was added to 3-days grown cells.

According to the results obtained, three concentrations, $0.35,0.5$, and $1 \mathrm{mg} / \mathrm{mL}$, were selected as the working concentrations for the biotransformation experiments. Berberine was added to 3-days grown $C$. lunata cells and the disappearance of berberine was followed for 14 days.

\subsection{Analysis of Biotransformation}

The disappearance of berberine was monitored using HPLC. Samples with different berberine concentrations were prepared and they were injected into the HPLC system using Acn: $\mathrm{H}_{2} \mathrm{O}$ (10:90) as the mobile phase. The retention time of berberine was determined to be between 3.5 -4 min. Residual berberine amounts of the biotransformation reactions were monitored using the same procedure.

HPLC results showed that the concentration of berberine in PDB was effectively reduced by C. lunata if it was below $1 \mathrm{mg} / \mathrm{mL}$. C. lunata cells degraded $99 \%$ and $87 \%$ of berberine with the initial concentrations of $0.35 \mathrm{mg} / \mathrm{mL}$ and $0.5 \mathrm{mg} / \mathrm{mL}$, respectively, after 14 days of incubation. The change in berberine concentration was negligible with $1 \mathrm{mg} / \mathrm{mL}$ berberine because of the slow cell growth at this concentration. Only $15.7 \%$ of the berberine was degraded in the same period (Figure 2). The intracellular accumulation of berberine was negligibly small for all working concentrations.

Figure 2. HPLC analysis of residual berberine amounts for $0.35,0.5$, and $1 \mathrm{mg} / \mathrm{mL}$ berberine concentrations.

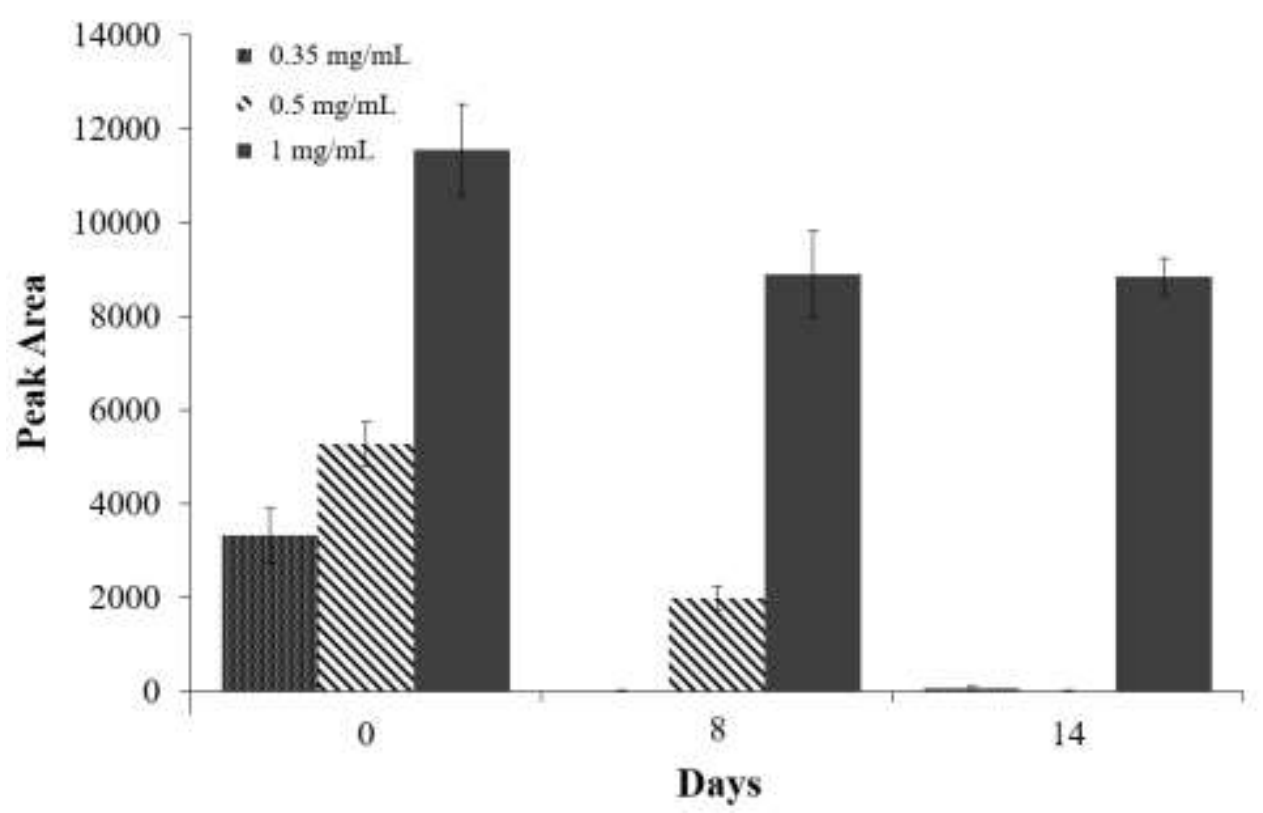

Additionally, thin layer chromatography (TLC) was applied to $14^{\text {th }}$ day samples with initial concentrations of 0.35 and $0.5 \mathrm{mg} / \mathrm{mL}$ berberine. The results of the study confirm that C. lunata can degrade the available berberine. However, more interestingly, although berberine was consumed by the cells, no other alkaloid was observed as the biotransformation product after the HPLC analysis and TLC. 


\subsection{Enzyme Activities During Biotransformation}

Biotransformation of chemicals is commonly achieved with the help of different enzymes synthesized by the cells and their concentrations/activities can give clues about the transformation pathway. Sing et al. (2017) investigated the biodegradation of ciprofloxacin by Pleurotus ostreatus through examining the effect of ciprofloxacin on the growth rate and enzyme activity. It was observed that ciprofloxacin had stimulated the enzymatic activity of the fungus (Singh et al., 2017). C. lunata produces several extracellular enzymes including betaglucosidase and laccase (Banerjee, 1992). In the light of this information, enzymatic assays were performed to research laccase and beta-glucosidase activities in our study. Since there was no significant change in the concentration for $1 \mathrm{mg} / \mathrm{mL}$ berberine, the effects of 0.35 and 0.5 $\mathrm{mg} / \mathrm{mL}$ of berberine on laccase and beta-glucosidase activities in C. lunata were determined after 8 and 14 days of incubation.

\subsubsection{Laccase activity}

In a previous study, Coman et al. (2013) searched for laccase inducers in the Chelidonium majus extract including berberine $(26 \mu \mathrm{g} / \mathrm{mL})$. The results showed that berberine did not show any effects on the laccase activity of Sclerotinia sclerotiorum at all concentrations between $1 \%$ and 4\% C. majus extract (Coman et al., 2013). Motivated by this work, the change in laccase activity was investigated in our specific study as well.

When the results of the laccase activity assay were examined (Figure 3), no significant change in activity was observed at different concentrations of berberine. However, at 0.5 $\mathrm{mg} / \mathrm{mL}$ berberine concentration, although there was a decrease in the growth rate up to $50 \%$, the laccase activity was relatively higher than that in other samples. This might point out a correlation between laccase and berberine degradation. Besides, it should be kept in mind that laccase could be a part of the defensive mechanism of the microorganism, as reported previously (Coman et al., 2013).

Figure 3. Effect of berberine on laccase activity.

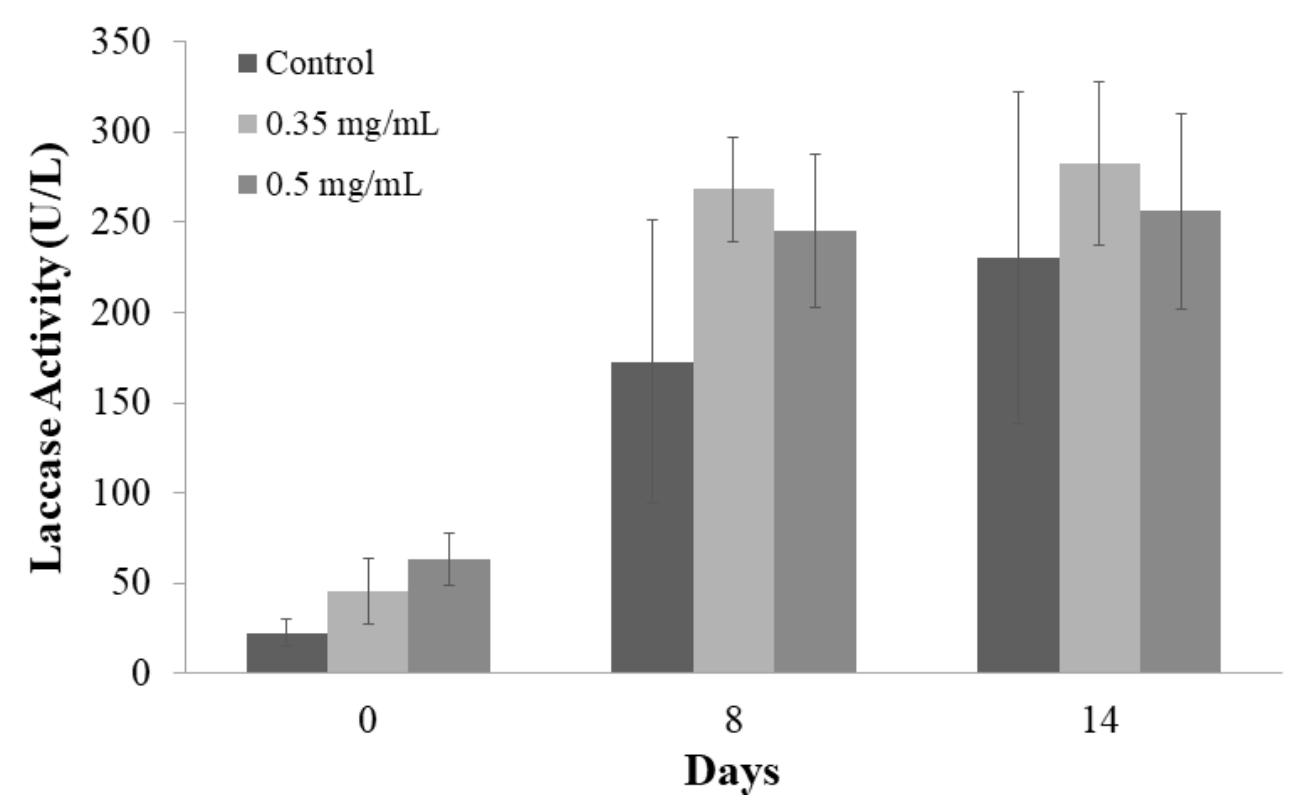

\subsubsection{Beta-glucosidase activity}

The color interference of berberine during the measurement of beta-glucosidase activity has led to inconsistent results with high standard deviations. However, in general, these results indicate no significant changes in the extracellular beta-glucosidase activity. 


\section{CONCLUSION}

In this study, berberine biotransformation by $C$. lunata was evaluated. 0.35 and $0.5 \mathrm{mg} / \mathrm{mL}$ berberine concentrations were selected as working concentrations based on the growth experiments. The change in the concentration of berberine was followed using HPLC. Since biotransformation reactions were carried out by the enzymes, laccase and beta-glucosidase activities were measured for their effects on the biotransformation of berberine. In addition, the samples were checked by TLC for the formation of possible products.

The results show that $C$. lunata consumed almost $100 \%$ of berberine after 14 days of incubation. No significant changes were observed in the laccase or beta-glucosidase activities. Although berberine was consumed by the cells, no spots regarding biotransformation products were detected on the TLC plates. Nuclear magnetic resonance spectroscopy (NMR) or mass spectrometry (MS) analyses could be performed to search for different biotransformation products of berberine. Monitoring these products will be helpful to enlighten the berberine biodegradation/biotransformation pathway(s) with the key enzymes which play important roles in the discovery of new valuable products and bioactive compounds.

\section{Acknowledgments}

This work is supported by Marmara University, Scientific Research Projects Committee (FENC- 070317-0110).

\section{Declaration of Conflicting Interests and Ethics}

The authors declare no conflict of interest. This research study complies with research and publishing ethics. The scientific and legal responsibility for manuscripts published in IJSM belongs to the authors.

\section{Authorship contribution statement}

Deniz Yilmaz: Performing the experiments and Writing. Fatma Gizem Avci: Writing, Editing, and Validation. Berna Sariyar Akbulut: Design of the study, Supervision, and Editing.

Orcid

Deniz Yilmaz (iD) https://orcid.org/0000-0003-1428-5708

Fatma Gizem Avci (iD https://orcid.org/0000-0001-6618-0487

Berna Sariyar Akbulut (iD https://orcid.org/0000-0002-4455-1192

\section{REFERENCES}

Avci, F.G., Sayar, N.A., \& Sariyar Akbulut, B. (2018). An OMIC approach to elaborate the antibacterial mechanisms of different alkaloids. Phytochemistry, 149, 123-131. https://doi.org/10.1016/j.phytochem.2017.12.023

Banerjee, U. C. (1992). Immobilized beta-glucosidase from Curvularia lunata. Folia Microbiologica, 37(4), 256-260. https://doi.org/10.1007/BF02814559

Bianchini, L.F., Arruda, M.F.C., Vieira, S.R., Campelo, P.M.S., Grégio, A.M.T., \& Rosa, E.A.R. (2015). Microbial biotransformation to obtain new antifungals. Frontiers in Microbiology, 6, 1433. https://doi.org/10.3389/fmicb.2015.01433

Bukvicki, D., Novaković, M., Ilić-Tomić, T., Nikodinović-Runić, J., Todorović, N., Veljić, M., \& Asakawa, Y. (2021). Biotransformation of Perrottetin F by Aspergillus niger: New Bioactive Secondary Metabolites. Records of Natural Products, 15(4), 281-292. https://doi.org/10.25135/rnp.215.20.09.1812

Collins, D.O., Buchanan, G.O., Reynolds, W.F., \& Reese, P.B. (2001). Biotransformation of squamulosone by Curvularia lunata ATCC 12017. Phytochemistry, 57(3), 377-383. https://doi.org/10.1016/S0031-9422(01)00060-7

Coman, C., Moţ, A.C., Gal, E., Pârvu, M. \& Silaghi-Dumitrescu, R. (2013). Laccase is 
upregulated via stress pathways in the phytopathogenic fungus Sclerotinia sclerotiorum. Fungal Biology, 117(7-8), 528-539. https://doi.org/10.1016/i.funbio.2013.05.005

Eliwa, D., Albadry, M. A., Ibrahim, A.R.S., Kabbash, A., Meepagala, K., Khan, I.A., El-Aasr, M., \& Ross, S.A. (2021). Biotransformation of papaverine and in silico docking studies of the metabolites on human phosphodiesterase 10a. Phytochemistry, 183, 112598. https://doi.org/10.1016/j.phytochem.2020.112598

Fura, A. (2006). Role of pharmacologically active metabolites in drug discovery and development. Drug Discovery Today, 11(3-4), 133-142. https://doi.org/10.1016/S1359$\underline{6446(05) 03681-0}$

Giri, A., Dhingra, V., Giri, C.C., Singh, A., Ward, O.P., \& Narasu, M.L. (2001). Biotransformations using plant cells, organ cultures and enzyme systems: Current trends and future prospects. Biotechnology Advances, 19(3), 175-199. https://doi.org/10.1016/S07349750(01)00054-4

Liu, J.H., \& Yu, B.Y. (2010). Biotransformation of bioactive natural products for pharmaceutical lead compounds. Current Organic Chemistry, 14(14), 1400-1406. https://doi.org/10.2174/138527210791616786

Pervaiz, I., Ahmad, S., Madni, M.A., Ahmad, H., \& Khaliq, F.H. (2013). Microbial biotransformation: a tool for drug designing (Review). Prikladnaia Biokhimiia Mikrobiologiia, 49(5), 435-449. https://doi.org/10.7868/s0555109913050097

Rozzell, J.D. (1999). Commercial scale biocatalysis: myths and realities. Bioorganic \& Medicinal Chemistry, 7(10), 2253-2261. https://doi.org/10.1016/S0968-0896(99)00159-5

Schmeda-Hirschmann, G., Astudillo, L., \& Palenzuela, J.A. (2004). Biotransformation of solidagenone by Alternaria alternata, Aspergillus niger, and Curvularia lunata cultures. World Journal of Microbiology and Biotechnology, 20(1), 93-97. https://doi.org/10.1023/B :WIBI.0000013317.60257.33

Singh, S.K., Khajuria, R., \& Kaur, L. (2017). Biodegradation of ciprofloxacin by white rot fungus Pleurotus ostreatus. 3 Biotech, 7(1), 1-8. https://doi.org/10.1007/s13205-017-0684y

Sultana, N. (2018). Microbial biotransformation of bioactive and clinically useful steroids and some salient features of steroids and biotransformation. Steroids, 136, 76-92. https://doi.org/10.1016/j.steroids.2018.01.007

Venisetty, R., \& Ciddi, V. (2003). Application of microbial biotransformation for the new drug discovery using natural drugs as substrates. Current Pharmaceutical Biotechnology, 4(3), 123-140. https://doi.org/10.2174/1389201033489847 